\title{
Effects of Starch/ Polycaprolactone-based Blends for Spinal Cord Injury Regeneration in Neurons/Glial Cells Viability and Proliferation
}

\author{
A. J. SAlgado, ${ }^{1}$ R. A. SOUSA, ${ }^{2,3}$ J. S Fraga, ${ }^{1}$ J. M. PEgo, ${ }^{1}$ B. A. Silva $^{4}$ \\ J. O. MALVA, ${ }^{4,5}$ N. M. NeVES, ${ }^{2,3}$ R. L. ReIS ${ }^{2,3}$ AND N. SousA ${ }^{1, *}$ \\ ${ }^{1}$ Life and Health Sciences Research Institute (ICVS), School of Health \\ Sciences, University of Minho, 4710-057 Braga, Portugal \\ ${ }^{2} 3 B$ 's Research Group - Biomaterials, Biodegradables and Biomimetics, \\ University of Minho, Headquarters of the European Institute of \\ Excellence on Tissue Engineering and Regenerative Medicine \\ AvePark, 4806-909 Taipas, Guimarães, Portugal \\ ${ }^{3} I B B$, Institute for Bioengineering and Biotechnology, PT Associated Lab \\ 4710-57 Braga, Portugal \\ ${ }^{4}$ Centre for Neuroscience and Cell Biology, University of Coimbra \\ 3004-504 Coimbra, Portugal \\ ${ }^{5}$ Institute of Biochemistry, Faculty of Medicine, University of Coimbra \\ 3004-504 Coimbra, Portugal
}

\begin{abstract}
Spinal cord injury (SCI) leads to drastic alterations on the quality of life of afflicted individuals. With the advent of Tissue Engineering and Regenerative Medicine where approaches combining biomaterials, cells and growth factors are used, one can envisage novel strategies that can adequately tackle this problem. The objective of this study was to evaluate a blend of starch with poly( $\varepsilon$-caprolactone) (SPCL) aimed to be used for the development of scaffolds spinal cord injury (SCI) repair. SPCL linear parallel filaments were deposited on polystyrene coverslips and assays were carried out using primary
\end{abstract}

*Author to whom correspondence should be addressed. E-mail: njcsousa@ecsaude.uminho.pt Figures 1-3 appear in color online: http://jbc.sagepub.com 
cultures of hippocampal neurons and glial cells. Light and fluorescence microscopy observations revealed that both cell populations were not negatively affected by the SPCL-based biomaterial. MTS and total protein quantification indicated that both cell viability and proliferation rates were similar to controls. Both neurons and astrocytes occasionally contacted the surface of SPCL filaments through their dendrites and cytoplasmatic processes, respectively, while microglial cells were unable to do so. Using single cell $\left[\mathrm{Ca}^{2+}\right]_{\mathrm{i}}$ imaging, hippocampal neurons were observed growing within the patterned channels and were functional as assessed by the response to a $30 \mathrm{mMKCl}$ stimulus. The present data demonstrated that SPCL-based blends are potentially suitable for the development of scaffolds in SCI regenerative medicine.

KEY WORDS: biodegrable polymers, starch-poly( $\varepsilon$-caprolactone) blends, cytotoxicity, neurons, glial, spinal cord injury, tissue engineering.

\section{INTRODUCTION}

$\mathbf{C}$ entral nervous system (CNS) disorders, caused by disease or injury, are typically debilitating and often lead to the premature death of the afflicted individuals. These disorders often pose challenges that are mainly related to the low regenerative potential of the CNS. Spinal cord injury (SCI) currently affects $\sim 10,000$ individuals in the United States every year [1,2]. These are commonly the result of compression to the cord, or alternatively, due to the sectioning of the latter [3]. The consequences of these injuries are devastating as the spinal tissue lacks the capacity to regenerate itself due to the secretion of inhibitory molecules after the injury occurs, the formation of a glial scar, induction of apoptosis, and the lack of neuro-regenerative factors $[3,4]$. Current strategies for SCI patients are based on the use of pharmacological agents such as methylprednisolone and minocycline, which prevent further damage in the affected areas but do not induce regeneration themselves.

The advances in the neurosciences/neuroregeneration field have led to the development novel methodologies to induce SCI regeneration, such as the transplantation of tissue/cell grafts like peripheral nerves [5] and Schwann cells [6-8]. CNS-derived cell-based therapy studies have also examined olfactory sheating cells (OECs) [9,10] and neural stem cells $[11,12]$ as potentially useful in SCI regenerative medicine.

Recent developments in tissue engineering have also provided new strategies to induce SCI regeneration, such as the development of a new generation of guidance scaffolds that promote axonal and nerve regeneration within its structure [13-15]. The latter possess the advantage of simultaneously acting as drug delivery devices, through the release of neuro-trophic factors which are known to have beneficial 
effects when injected into SCI sites, or as a support for specific cell populations, such as neural stem cells and OECs, to induce regeneration in SCI affected areas [3].

The development of this new generation of nerve guidance conduits has been stimulated by the advent of new polymeric materials, as well as, novel scaffold processing techniques [16]. Biodegradable materials from both synthetic or natural origin, such as PHPMA, pHEMA-MMA, PEG, fibrin, collagen, fibrinogen, agarose, and alginate have been put forward as possible options for the development of SCI regeneration guidance tubes [3]. Other strategies include blends of natural and synthetic polymers, such as PCL with collagen/fibrin [17]. Natural-based polymers are quite appealing for biomedical applications due to their chemical versatility and low immunogenic responses. For instance collagen, dextran, or chitosan have been proposed for SCI-related applications in a variety of systems, from hydrogels to 3D scaffolds [17-20].

Another interesting material for the above application is starch, or in this case, starch thermoplastic blends. Starch is a polysaccharide comprised of $\alpha$-D-glucose units organized in two distinct macromolecules forms, amylase and amylopectin [21]. An advantage of using polysaccharide-based biomaterials is they may act as analogs of polysaccharides present in vivo [22]. Starch-based polymeric systems have been proposed for a wide range of biomedical applications, including tissue engineering scaffolds [23-26]. These starch-based polymeric systems are commonly blended with thermoplastic polymers, such as, poly( $\varepsilon$-caprolactam) (PCL) to enhance processability, resistance to thermomechanical degradation, and improve mechanical performance [21]. When compared to the more commonly used biodegradable polymers in the field it has the advantage of forming flexible structural designs with adequate mechanical properties since it can be processed by extrusion with blowing agents, fiber bonding, and rapid prototyping. Due to this versatility, one can envision guidance conduits, including those that could combine a thermoplastic biodegradable polymer with hydrogel-based biomaterials. One possible approach would be to combine the thermoplastic properties of starchbased polymers that have favorable mechanical properties and the guidance capability of hydrogels such as those described by Luo and Shoichet [27]. These materials have shown a positive biocompatible response, even when compared to the more traditional aliphatic polyesters, such as poly(lactic-acid) (PLA), poly(glycolic-acid) (PGA) or their copolymers [28-30]. However, its application to the CNS is yet to be tested. Therefore, the objective of the present work was to evaluate the effects of a biodegradable blend of starch with polycaprolactone (SPCL) on the viability and proliferation of CNS-derived cells, such as neurons and glial cells. 


\section{EXPERIMENTAL MATERIALS AND METHODS}

\section{SPCL Patterning}

The material used in this study was a blend of starch with poly $(\varepsilon-$ caprolactam) (SPCL), with $\sim 30 \% \mathrm{w} / \mathrm{w}$ corn starch. This blend was processed according to the methods reviewed by Reis et al. [21]. SPCL patterns were produced on the surface of poly(D-lysine)-coated polystyrene coverslips (1.3 cm diameter) using a rapid prototyping technology: 3D bioplotting (Bioplotter ${ }^{\mathrm{TM}}$, EnvisionTec GmbH, Germany). Parallel SPCL filaments with a diameter of $0.4 \mathrm{~mm}$ were patterned at relative distances of $0.5 \mathrm{~mm}$. Figure 1 presents a patterned cover slip.

\section{Hippocampal Neurons Cell Culture}

Hippocampal neuron cultures were prepared from P4 Wistar Rats [31]. Upon dissection, hippocampus tissue samples were submitted to a 10 min trypsin-based enzymatic digestion (0.05\% Trypsin - Gibco; $3 \mathrm{mg} / \mathrm{mL}$ BSA - Sigma; 0.0025\% DNase - Sigma, in EBSS - Gibco) followed by mechanical dissociation and centrifugation. The isolated

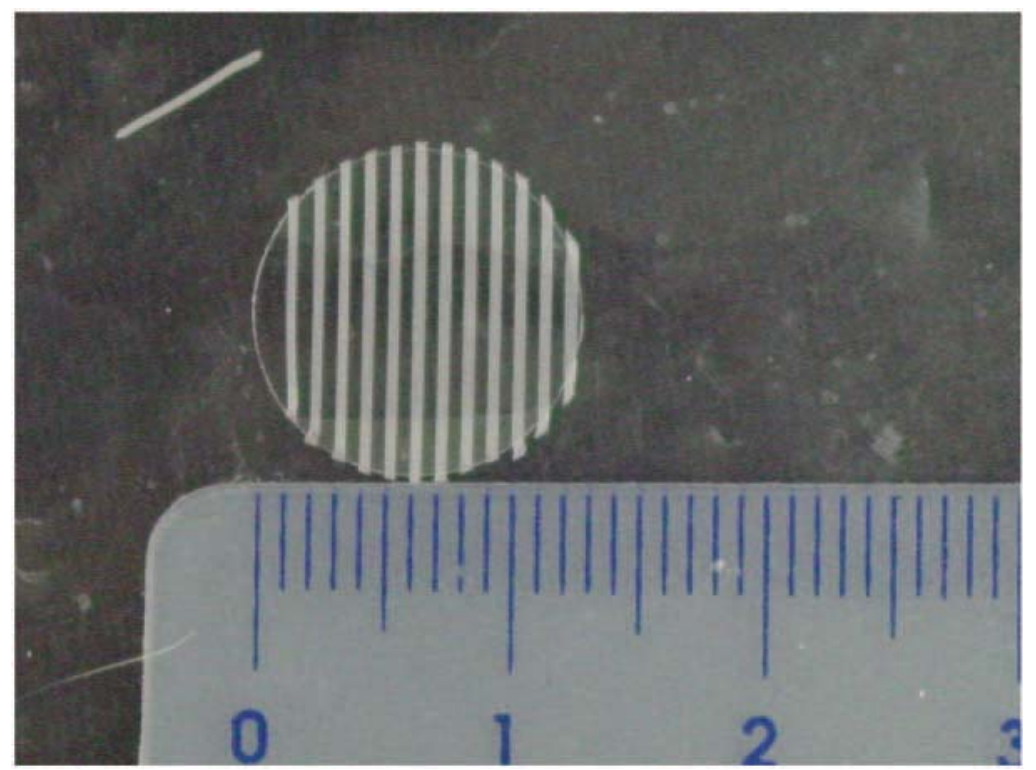

Figure 1. SPCL patterned channels had $1-2 \mathrm{~mm}$ width and were obtained by using rapid prototyping (3D bioplotting). 
cells were then plated on the SPCL patterned coverslips at a density of $4 \times 10^{4}$ cells $/ \mathrm{cm}^{2}$. Poly(D-lysine) coated nonpatterned coverslips were used as controls. The cultures were maintained at $37^{\circ} \mathrm{C}, 5 \% \mathrm{CO}_{2} / 95 \%$ air, 90\% relative humidity in Neurobasal A medium supplemented with B27, $1 \mathrm{mM}$ GlutamaxI, $10 \mathrm{ng} / \mathrm{mL}$ basic fibroblast growth factor (bFGF) and $0.1 \mathrm{mg} / \mathrm{mL}$ kanamycin (all from Gibco, USA) for 7 days.

\section{Cortical Glial Cells}

Cortical glial cells were isolated from P4 newborns (Wistar Rats). After dissection, the cortices were submitted to an enzymatic cocktail (30 mg/mL DNase, $0.25 \%$ trypsin, both from Sigma) in $\mathrm{Ca}^{2+} / \mathrm{Mg}^{2+}$ free HBSS (Gibco) followed by mechanical dissociation. Glial cells were then obtained by centrifuging the resulting cells suspension at $800 \mathrm{rpm}$ for 2 min and plated out on SPCL patterned coverslips previously coated with poly(D-Lysine) at a density of $4 \times 10^{4}$ cells $/ \mathrm{cm}^{2}$. Poly(D-Lysine) coated nonpatterned coverslips were used as controls. Cells were then maintained for 14 days in Dulbecoo's Modified Eagle Medium (DMEM, Sigma), supplemented with $10 \%$ fetal bovine serum (FBS, Gibco) and 1\% antibiotic/antimicotics (Sigma).

\section{Cell Viability Assessment}

After days 7 and 14, cell viability was assessed by the MTS test for the neuron and glial cells, respectively. The MTS test is an assay whereby the substrate - MTS - is reduced into a brown formazan product by $\mathrm{NADPH}$ or NADP produced by mitochondrial enzymes, that are active in living cells $[32,33]$. The SPCL patterned and control coverslips $(n=3)$ were placed in culture medium containing MTS in a 5:1 ratio and incubated in a humidified atmosphere at $37^{\circ} \mathrm{C}$ and $5 \% \mathrm{CO}_{2}$. After incubation for $3 \mathrm{~h}, 100 \mu \mathrm{L}$ of solution from each well were transferred to 96 well plates and the optical density determined at $490 \mathrm{~nm}$.

\section{Total Protein Quantification}

For total protein quantification, the cells were first lysed by adding $300 \mu \mathrm{L} /$ well of ultra-pure water, after which samples $(n=3)$ and controls $(n=3)$ were frozen at $80^{\circ} \mathrm{C}$. The total protein was quantified by using the BCA Protein Assay kit (Pierce Chemical, USA). After the reduction, $100 \mu \mathrm{L}$ of each sample were transferred to a 96 -well plate where the absorbance was determined at $562 \mathrm{~nm}$ with a multi-well plate reader (Tecan, USA) and compared to a standard curve. 


\section{Immunocytochemistry}

Following the prescribed culture periods, the cells were fixed in $4 \%$ paraformaldheyde for $30 \mathrm{~min}$, permeabilized by incubation with $0.3 \%$ triton X-100 (Merck, Germany) in PBS at room temperature, and washed three times in PBS. The cells were then blocked with $10 \%$ FBS/PBS ( $60 \mathrm{~min})$ followed by a $60 \mathrm{~min}$ incubation with the following primary antibodies: mouse anti-rat microtubule associated protein 2 (MAP-2) (Sigma, USA, 1:500) to detect mature hippocampal neurons, rabbit anti-rat glial fibrillary acid protein (GFAP) (Dako, Denmark, 1:500) for astrocytes, mouse anti-CD11b (BD Biosciences Pharmigen, USA, $1: 100)$ for microglial cells and mouse anti-O4 (R\&D systems, USA, 1:50) for oligodendrocytes. Cells were then washed in PBS and incubated with a secondary antibody (1:2000): Alexa Fluor 594 goat anti-mouse immunoglobulin G (IgG) and Alexa Fluor goat anti-rabbit 488 (Molecular Probes, USA) for $60 \mathrm{~min}$. To produce negative control samples, the primary antibody was omitted. The samples were observed with Olympus BX-61 Fluorescence Microscope (Olympus, Germany) or a Confocal Laser Microscope (Zeiss, Germany).

\section{Single Cell $\left[\mathrm{Ca}^{2+}\right]_{\mathbf{i}}$ Imaging}

Hippocampal neurons were loaded by incubating with $5 \mu \mathrm{M}$ of fura2/AM (Molecular Probes) and 0.02\% Pluronic F-127 (Molecular Probes) for $45 \mathrm{~min}$, at $37^{\circ} \mathrm{C}$, in Krebs buffer supplemented with $0.1 \%$ BSA (w/v) [33]. After incubation, the patterned coverslips and controls were washed and placed in a perfusion chamber on the stage of an inverted Zeiss fluorescence microscope (Zeiss Germany). The cells were exposed to Krebs buffer $\left(37^{\circ} \mathrm{C}\right)$ for $\sim 5 \mathrm{~min}$ before data acquisition, followed by a 3 -min exposure to $30 \mathrm{mM} \mathrm{KCl}$ in Krebs solution. The neurons were stimulated for $15 \mathrm{~s}$, after starting image acquisition using MetaFluor software (Universal Imaging Corporation) in an Axiovert 200 epifluorescence inverted microscope (Zeiss), equipped with a Lambda DG-4 (Sutter Instrument Company) and a high-resolution LCD camera (CoolSnap HQ). Image acquisition was performed alternatively at 340/ $380 \mathrm{~nm}$ ( $300 \mathrm{~ms}$ exposure time, $10 \mathrm{~s}$ between acquisitions), using a Fura$2 /$ rhodamine filter. The fluorescence changes were recorded with a multiple excitation imaging system. The ratio of fluorescence excitation intensity at 340 and $380 \mathrm{~nm}$, as percentage of responding cells to the $\mathrm{KCl}$ stimulus, was determined. 


\section{Statistics}

Statistical evaluations were performed using two-tailed paired $t$-student tests, to assess the statistical differences between control and SPCL patterned coverslips. Statistical significance was defined as $p<0.05$ for a $95 \%$ confidence interval.

\section{RESULTS AND DISCUSSION}

SCI is a major health problem that needs innovative solutions and tissue engineered multi-component 3D nerve guidance conduits are amongst these possible strategies. It is believed that by following entubulation routes it will be possible to direct the regenerating axons to target sites, minimizing the migration of connective tissue into the injury site to prevent obstruction by scar tissue [17]. Biomaterials play a major role within tissue engineering strategies; therefore, how they interact with CNS derived cells is crucial for the development of a 3D conduit with the adequate characteristics to foster SCI regeneration.

In the present work, a model to study the influence of a biodegrable polymeric blend, SPCL, on the viability and proliferation of neurons and glial cells was developed. For this purpose SPCL fibers were first laid down on polystyrene coverslips (Figure 1), after which hippocampal neurons and cortical glial cells were seeded on these structures. The hippocampal cell cultures, characterized by immunocytochemistry, contained $\sim 50 \%$ mature neurons and $5-10 \%$ of astrocytes. Similar systems have also been reported to possess $\sim 40 \%$ neuroprogenitor cells [31]. In mature glial cells culture systems, the dominant cell type was microglia (45-55\%), followed by astrocytes (35-45\%) and oligodendrocytes (5-10\%). There was a small contamination by fibroblasts/ endothelial cells that usually represented less than $2 \%$ of the cultured cells. Therefore, the latter are believed to be satisfactory for the objectives of the present work since they incorporate all the cell types involved in SCI regeneration (neurons and neuroprogenitors present in hippocampal cultures) and the three subpopulations of glial cells (astrocytes, microglia, and oligodendrocytes).

In this study, qualitative analysis by light microscopy revealed that no significant cell death occurred and the presence of the SPCL rods did not affect cell proliferation and morphology (Figure 2). Both neurons and glial cells had similar morphologies when compared to the controls. Simultaneously, the hippocampal cultures had higher cell densities on the SPCL patterned coverslips compared to control cultures. This may 


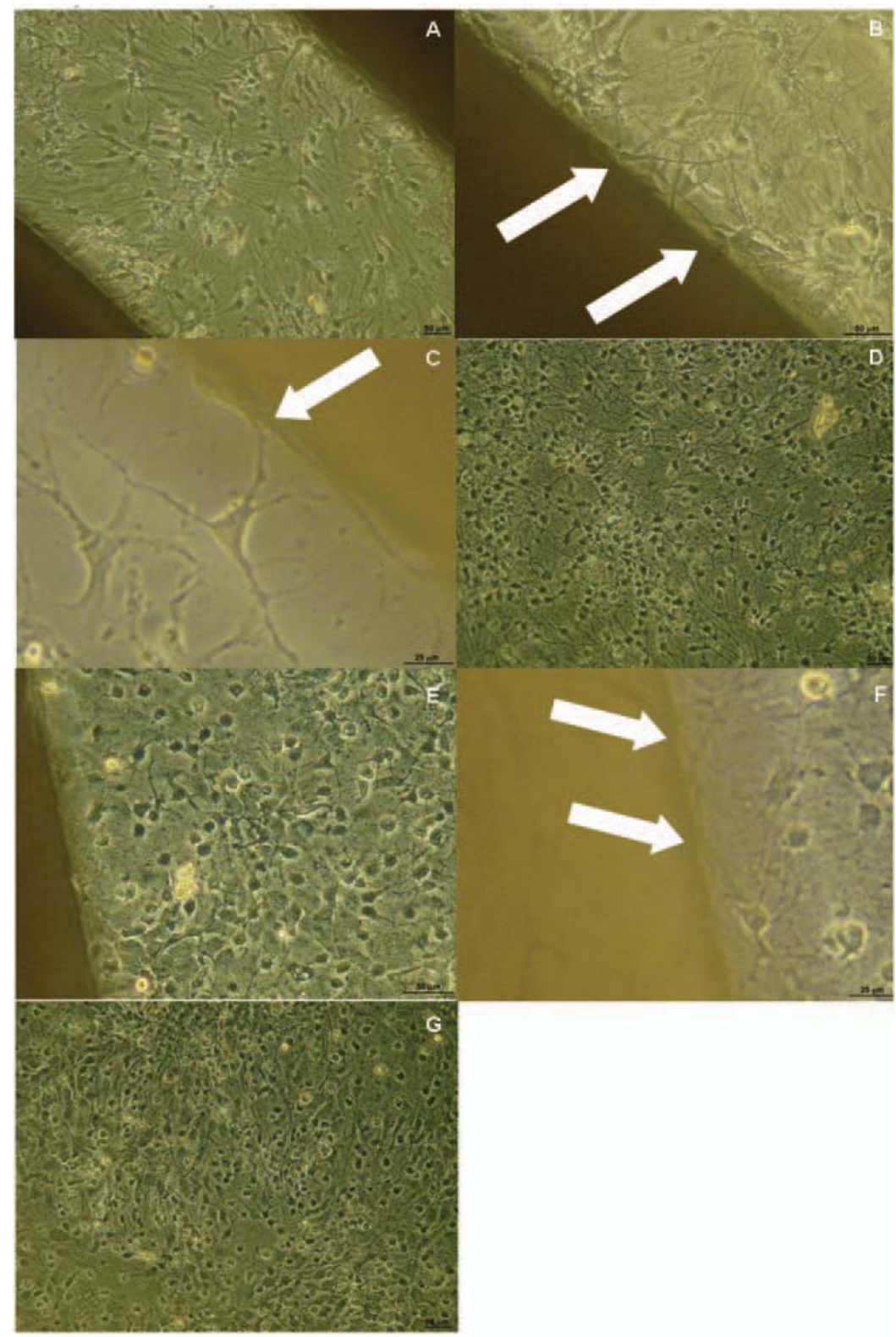

Figure 2. Light microscopy micrographs of neurons (A-C) and glial cells $(\mathrm{E}, \mathrm{F})$ growing within the SPCL patterned channels. Both cell populations had morphologies similar to the controls (hippocampal neurons (D) and glial cells (G)). A closer observation revealed that neurons and glial cells were intermittently contacting the surface of the biomaterial (arrows in B,C,F) (scale bar: A,B,D,E,G $50 \mu \mathrm{m}$; C, F $25 \mu \mathrm{m}$ ). 
be explained by the reduced areas of cell growth caused by the presence of the SPCL filaments. Regarding glial cells, the densities near and away from the SPCL filaments were quite similar, fact that indicates the nondeleterious response caused by the biomaterial under test. Moreover, both hippocampal neurons and glial cells were intermittently in contact with the biomaterial (Figure 2(B, C, and F) arrows). These findings were further confirmed by immunostaining against different neuronal and glial markers, such as, MAP-2, GFAP, CD11b, and O4 (Figure 3). Confocal laser microscopy observations revealed that both mature hippocampal neurons (Figure 3(A)) and astrocytes (Figure 3(B)) were growing in the vicinity of the SPCL filaments. Furthermore, it was also observed that occasionally the dendrites (neurons) and cytoplasmatic processes (astrocytes) were directly contacting the biomaterial (arrows).

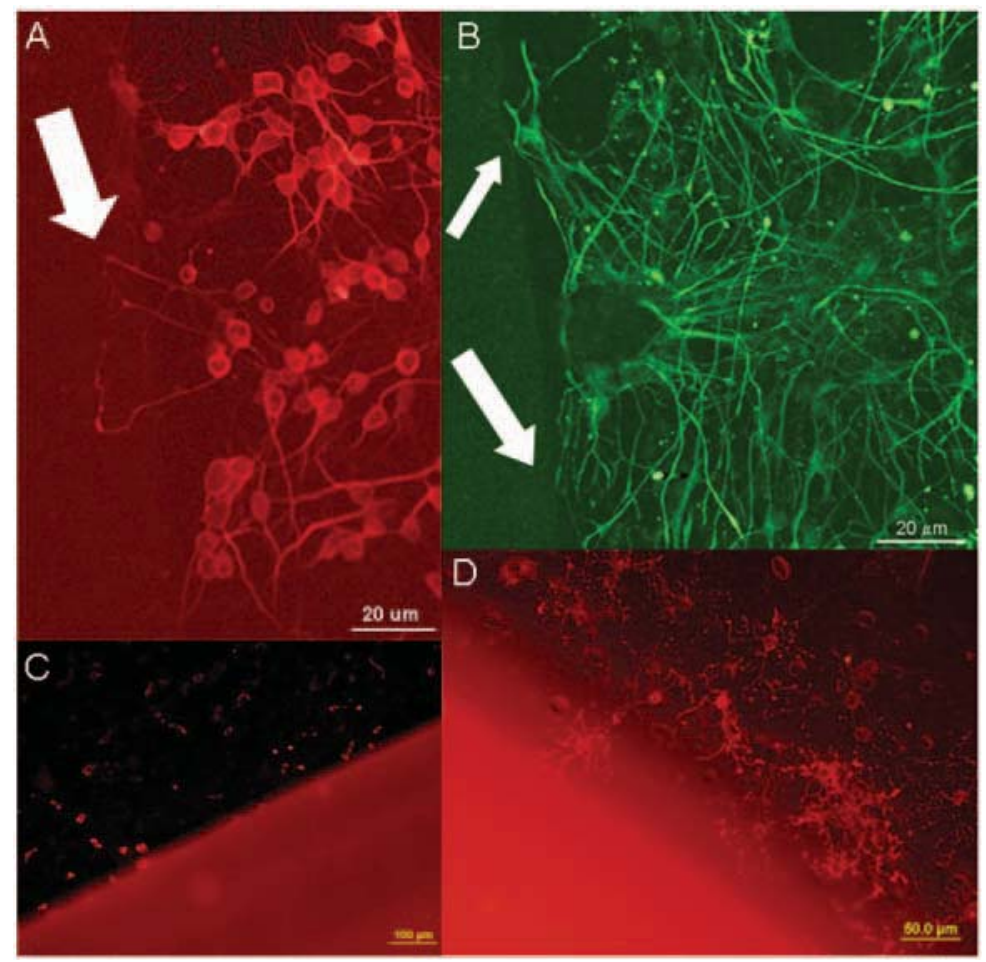

Figure 3. Confocal laser (A,B) and fluorescence microscopy (C,D) micrographs of MAP-2, GFAP, CD11b, and O4 stained neurons (A), astrocytes (B), microglial cells (C), and oligodendrocytes (D). Micrographs show that neurons and astrocytes were directly contacting the surface of the SPCL-based biomaterial (A,B - arrows). (scale bar: A,B $20 \mu \mathrm{m} ; \mathrm{C}-100 \mu \mathrm{m} ; \mathrm{D}-50 \mu \mathrm{m})$. 
Cell viability (hippocampal Neurons) - MTS test Cell viability (glial cells) - MTS test
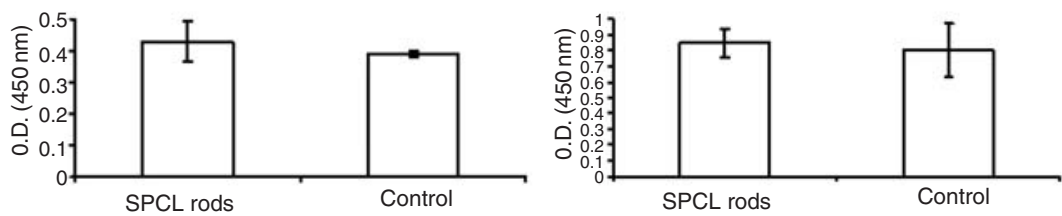

Figure 4. Cell viability was assessed by the MTS test. The metabolic activity of the cells growing on the SPCL patterned channels was similar to the control samples; therefore, the material was considered nontoxic to CNS-derived cells $(n=3$, mean $\pm \mathrm{SD}, p>0.05)$.

Moreover, it was also shown by fluorescence microcopy that microglial cells (Figure $3(\mathrm{C})$ ) were not adhering to the filaments. Also observed was that oligodendrocytes, the myelinating cells of the CNS, were preferably located towards the biomaterial when compared to the central areas of the channels (Figure 3(D)). In fact, no oligodendrocytes could be found in the central areas of the channels, as they were all located in the vicinity of the SPCL filaments, a property that might be of use to stimulate myelination of newly regenerated nerves.

Following these morphological observations, a series of experiments were conducted to evaluate the metabolic activity of these cells, as well as their proliferation rates and functionality. MTS test was used to determine the metabolic activity of hippocampal neurons and glial cells when cultured in the presence of the SPCL filaments. Both cell populations produced large amounts of a brown formazan product which is an indicator of normal metabolism (Figure 4). This indicated that the cells were able to incorporate and metabolize MTS and, hence, they were viable. Furthermore, the registered OD levels were very similar to those obtained by the control samples $(p>0.05)$, which supports our claim regarding the low cytotoxicity of the tested SPCL based biomaterial on neurons and glial cells.

The data obtained with the MTS test was subsequently confirmed by cell proliferation assays, through the quantification of the total protein (Figure 5). Similar to the results achieved by the MTS tests no differences were found between the tested and control samples $(p>0.05)$, it was demonstrated that cell proliferation of both cell populations was not affected by the presence of SPCL filaments.

To assess whether the neurons growing in the patterned channels were functionally viable, single cell $\left[\mathrm{Ca}^{2+}\right]_{\mathrm{i}}$ variations upon specific neuron stimuli with $30 \mathrm{mMKCl}$ were done according to previously described protocols [34]. The latter is particular useful as it leads to the depolarization of neuronal cells, and hence screens whether cell 
Cell proliferation (hippocampal neurons)

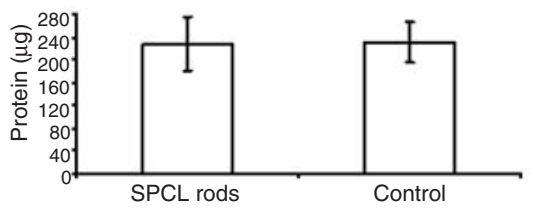

Cell proliferation (glial cells)

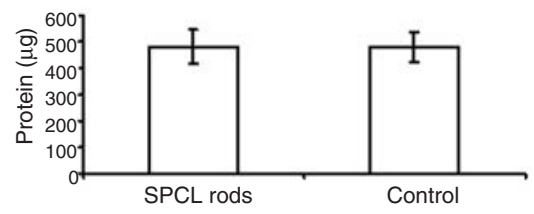

Figure 5. Cell proliferation was determined by quantification of the total protein. The levels of protein obtained from the cells growing in the presence of the SPCL filaments was similar to the control samples, indicating that the latter is not deleterious for both cell populations $(n=3$, mean $\pm \mathrm{SD}, p>0.05)$.

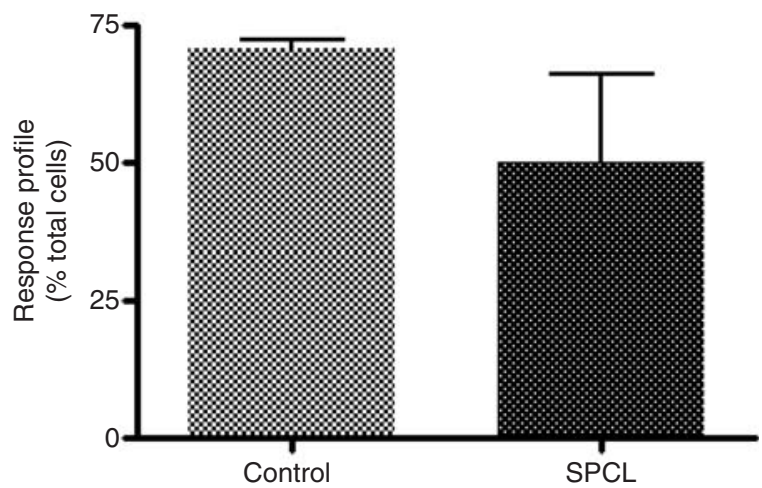

Figure 6. Percentage of cells, within hippocampal cultures, responding to $30 \mathrm{mM} \mathrm{KCL}$, obtained by single cell $\left[\mathrm{Ca}^{2+}\right]_{\mathrm{i}}$ for both control and SPCL patterned coverslips $(n=3$, mean $\pm \mathrm{SD}, p>0.05)$.

functionality has been impaired. As seen in Figure 6, approximately 50\% of the hippocampal neurons responded to the stimulus. Even though this response profile was diminished when directly compared to the control samples $(\sim 75 \%)$, this could be attributed to the high cell densities obtained within the channels, which delayed the establishment of the needed dendritic networks, and thus lead to a decrease on the number of responding cells.

\section{CONCLUSIONS}

In the present work, it was demonstrated that a biodegradable polymeric blend of starch with poly( $\varepsilon$-caprolactam) presents a range of properties that are believed to be adequate for future studies on CNS tissue engineering/regenerative medicine. 
This blend displayed a non-cytotoxic behavior with a biocompatible profile based on the fact that no neuronal or glial cell death was detected when directly compared to controls. In addition, both neurons and astrocytes were intermittently contacting the biomaterial. Finally, single cell $\left[\mathrm{Ca}^{2+}\right]_{\mathrm{i}}$ imaging revealed that neurons growing in the SPCL patterned channels were functionally viable. These preliminary findings are encouraging for the future development of these 3D scaffolds for SCI regeneration. To overcome the limitations of the $2 \mathrm{D}$ cell culture system, 3D SPCL-based systems that resemble the environment found in SCI sites will be used in future studies.

\section{ACKNOWLEDGMENTS}

Portuguese Foundation for Science and Technology through funds from POCTI and/or FEDER programs (Funding to ICVS, 3B's Research Group and post doctoral fellowship to A.J. Salgado - SFRH/BPD/17595/2004).

\section{REFERENCES}

1. Berkowitz, M., Harvey, C., Greene, C.G. and Wilson, S.E. (1992). The Economic Consequences of Traumatic Spinal Cord Injury, Demos Publication, New York.

2. Sekhon, L.H. and Fehlings, M.G. (2001). Epidemiology, Demographics, and Pathophysiology of Acute Spinal Cord Injury, Spine, 26: S2-S12.

3. Samadikuchaksaraei, A. (2007). An Overview of Tissue Engineering Approaches for Management of Spinal Cord Injuries, J. NeuroEng. Rehab., 4: 15-31.

4. Silver, J. and Miller, J.H. (2005). Regeneration Beyond the Glial Scar, Nat. Rev. Neurosci., 5: 146-56.

5. Houle, J.D., Tom, V.J., Mayes, D., Wagoner, G., Phillips, N. and Silver, J. (2006). Combining an Autologous Peripheral Nervous System "Bridge" and Matrix Modification by Chondroitinase Allows Robust, Functional Regeneration Beyond a Hemisection Lesion of the Adult Rat Spinal Cord, J. Neurosci., 26(28): 7405-7415.

6. Guest, J.D., Rao, A., Olson, L., Bunge, M.B. and Bunge, R.P. (1997). The Ability of Human Schwann Cell Grafts to Promote Regeneration in the Transected Nude Rat Spinal Cord, Exp. Neurol., 148: 502-22.

7. Xu, X.M., Guenard, V., Kleitman, N. and Bunge, M.B. (1995). Axonal Regeneration into Schwann Cell-seeded Guidance Channels Grafted into Transected Adult-Rat Spinal-cord, J. Comp. Neurol., 351: 145-60.

8. Fibouzi, M., Moshayedi, P., Saberi, H., Mobasheri, H., Abolhassani, F., Jahanzad, I. et al. (2006). Transplantation of Schwann Cells to Subarachnoid Space Induces Repair in Contused Rat Spinal Cord, Neurosci. Lett., 10: 66-70. 
9. Pastrana, E., Moreno-Flores, M.T., Gurzov, E.N., Avila, J., Wandosell, F. and Diaz-Nido, J. (2006). Genes Associated with Adult Axon Regeneration Promoted by Olfactory Ensheating Cells: A New Role for Matrix Metalloproteinase 2, J. Neurosci., 26: 5347-5359.

10. Ramon-Cueto, A., Cordero, M.T., Santos-Benito, F.F. and Avila, J. (2000). Functional Recovery of Paraplegic Rats and Motor Axon Regeneration in their Spinal Cords by Olfactory Ensheating Glia, Neuron, 25: 425-435.

11. Yan, J., Xu, L., Welsh, A.M., Hatfield, G., Hazel, T., Johe, K. et al. (2007). Extensive Neuronal Differentiation of Human Neural Stem Cell Grafts in Adult Rat Spinal Cord, PLOS Medicine, 4(2): 318-332.

12. Cummings, B.J., Uchida, N., Tamaki, S.J., Salazar, D.L., Hooshmand, M., Summers, R. et al. (2005). Human Neural Stem Cells Differentiate and Promote Locomotor Recovery in Spinal Cord-injured Mice, PNAS, 102: 14069-14074.

13. Moore, F.J., Friedman, J.A., Lewellyn, E.B., Mantila, S.M., Krych, A.J., Ameenuddin, S. et al. (2006). Multiple-channel Scaffolds to Promote Spinal Cord Axon Regeneration, Biomaterials, 27: 419-429.

14. Zhang, N., Yan, H. and Wen, X. (2005). Tissue-engineering Approaches for Axonal Guidance, Brain Res. Rev., 49: 48-64.

15. Schmidt, C.E. and Leach, J.B. (2003). Neural Tissue Engineering: Strategies for Repair and Regeneration. Annu. Rev. Biomed. Eng., 5: 293-347.

16. Wen, X. and Tresco, P.A. (2006). Fabrication and Characterization of Permeable Degradable Poly(DL-lactide-co-glycolide) (PLGA) Hollow Fiber Phase Inversion Membranes for Use as Nerve Tract Guidance Channels, Biomaterials, 27: 3800-3809.

17. Schnell, E., Klinkhammer, K., Balzer, S., Brook, G., Klee, D., Dalton, P. et al. (2007). Guidance of Glial Cell Migration and Axonal Growth on Electrospun Nanofibers of Poly-Epsilon-Caprolactone and a Collagen/PolyEpsilon-Caprolactone Blend, Biomaterials, 28(19): 3012-3025.

18. Freier, T., Montenegro, R., Koh, H.S. and Shoichet, M.S. (2005). Chitinbased Tubes for Tissue Engineering the Nervous System, Biomaterials, 26: 4624-4632.

19. Lévesque, S.G., Lim, R.M. and Shoichet, M.S. (2005). Macroporous Interconnected Dextran Scaffolds of Controlled Porosity for Tissueengineering Applications, Biomaterials, 26: 7436-7446.

20. Iwata, A., Browne, K.D., Pfister, B.J., Gruner, J.A. and Smith, D.H. (2006). Long Term Survival and Outgrowth of Mechanically Engineered Nervous Tissue Constructs Implanted into Spinal Cord Lesions, Tissue Eng., 12: 101-110.

21. Reis, R.L. and Cunha, A.M. (2001). Starch and Starch Based Thermoplastics, In: Jurgen Buschow, K.H., Cahn, R.W., Flemings, M.C., Ilschner, B., Kramer, E.J. and Mahajan, S. (eds), Encyclopedia of Materials Science and Technology, pp. 8810-8816, Pergamon-Elsevier Science, Amsterdam. 
22. Ding, Z., Chen, J., Gao, S., Chang, J., Zhang, J. and Kang, E.T. (2004). Immobilization of Chitosan Onto Poly-lactic Acid Film Surface by Plasma Graft Polymerization to Control the Morphology of Fibroblast and Liver Cells, Biomaterials, 25: 1059-1067.

23. Salgado, A.J., Gomes, M.E., Chou, A., Coutinho, O.P., Reis, R.L. and Hutmacher, D.W. (2002). Preliminary Study on the Adhesion and Proliferation of Starch Based Scaffolds, Mat. Sci. \& Eng. C, 22: 27-33.

24. Salgado, A.J., Coutinho, O.P. and Reis, R.L. (2004). Novel Starch Based Scaffolds for Bone Tissue Engineering: Cytotoxicity, Cell Culture and Protein Expression, Tissue Eng., 10: 465-474.

25. Mendes, S.C., Bezemer, J., Claase, M.B., Grijpma, D.W., Bellia, G., DegliInnocenti, F. et al. (2003). Evaluation of Two Biodegradable Polymeric Systems as Substrates for Bone Tissue Engineering, Tissue Eng., 9: S91-101.

26. Gomes, M.E., Sikavitsas, V.I., Behravesh, E., Reis, R.L. and Mikos, A.G. (2003). Effect of Flow Perfusion on the Osteogenic Differentiation of Bone Marrow Stromal Cells Cultured on Starch-based Three-dimensional Scaffolds, J. Biomed. Mat. Res. - Part A, 67(1): 87-95.

27. Luo, Y. and Shoichet, M.S. (2004). A Photolabile Hydrogel for Guided Threedimensional Cell Growth and Migration, Nat. Mater., 3(4): 249-253.

28. Marques, A.P., Reis, R.L. and Hunt, J.A. (2005). An In Vivo Study of the Host Response to Starch-based Polymers and Composites Subcutaneously Implanted in Rats, Macromol. Biosci., 5: 775-785.

29. Salgado, A.J., Coutinho, O.P., Reis, R.L. and Davies, J.E. (2007). In Vivo Response to Starch-based Scaffolds Designed for Bone Tissue Engineering Applications, J. Biomed. Mater. Res. A, 80(4): 983-989.

30. Salgado, A.J., Gomes, M.E. and Reis, R.L. (2004). Tissue Engineering of Mineralized Tissues: The Essential Elements, In: Reis, R.L. and Weiner, S. (eds), Learning from Nature How to Design New Implantable Materials, pp. 205-222, Kluwer Academic Publishers, Drodercht, The Netherlands.

31. Lu, J., Wu, Y., Sousa, N. and Almeida, O.F. (2005). SMAD Pathway Mediation of BDNF and TGF Beta 2 Regulation of Proliferation and Differentiation of Hippocampal Granule Neurons, Development, 132(14): 3231-3242.

32. Cory, A.H., Owen, T.C., Barltrop, J.A. and Cory, J.G. (1991). Use of an Aqueous Soluble Tetrazolium/Formazan Assay for Cell Growth Assays in Culture, Cancer Commun., 3(7): 207-212.

33. Salih, V., Franks, K., James, M., Hastings, G.W. and Knowles, J.C. (2000). Development of Soluble Glasses for Biomedical Use Part II: The Biological Response of Human Osteoblast Cell Lines to Phosphate-based Soluble Glasses, J. Mater. Sci.: Mater. Med., 11: 615-620.

34. Silva, A.P., Malva, J.O., Ambrosio, A.F., Salgado, A.J., Carvalho, A.P. and Carvalho, C.M. (2001). Role of Kainate Receptor Activation and Desensitization on the $\left[\mathrm{Ca}^{2+}\right]_{\mathrm{i}}$ Changes in Cultured Rat Hippocampal Neurons, J. Neurosci. Res., 65(5): 378-386. 